\title{
Experimental Response of RC Beams Strengthened in Shear by FRP Sheets
}

\author{
E. Grande, M. Imbimbo* and A. Rasulo \\ Department of Civil and Mechanical Engineering, University of Cassino and Southern Lazio, Italy
}

\begin{abstract}
The paper discusses the results of an experimental investigation carried out on reinforced concrete (RC) beams strengthened in shear by externally bonded fiber reinforced plastic (FRP) sheets. The study is devoted to analyze the role that the transverse steel reinforcement and the beam slenderness ratio could play on the resistant mechanism of RC beams strengthened in shear by FRP composites. The results are summarized and analyzed in detail in the paper in terms of shear capacity, cracking pattern and shear resisting contribution of FRP.
\end{abstract}

Keywords: Beam slenderness, cracking, FRP-shear strengthening, RC beams, steel stirrups.

\section{INTRODUCTION}

The use of composite materials, mainly fiber reinforced polymers (FRP) and, more recently, cement based composite and steel reinforced polymers (SRP), and steel reinforced grout (SRG), in the strengthening of existing RC and masonry structures [1-7] has become a common technique widely adopted in the past decade. Particularly for the case of RC structures, several studies (i.e. [8-12], etc.), together with code recommendations [13-15], testify the grade of awareness the research community has reached in the development of theoretical models and design rules to be adopted in the application of this strengthening technique.

Nevertheless, there are some aspects, which would require further investigations. Among these, the influence of the transverse steel reinforcement and of the slenderness ratio on the resistance mechanism of RC beams strengthened in shear by FRP is certainly an important issue. Indeed, the results emerged from recent experimental studies [16-29] have clearly pointed out that an interaction exists between the resisting mechanisms provided by steel stirrups and FRP. However, the theoretical formulations proposed by the actual codes for evaluating the shear contribution of FRP reinforcement neglect this aspect with the consequence of overestimating the contribution of FRP to shear resistance in some circumstances.

This paper aims at investigating experimentally the effect of the transverse steel and the slenderness ratio on the response of RC beams strengthened in shear by FRP. For this purpose, the results of an experimental investigation carried out by the authors on RC beams strengthened in shear by externally bonded FRP sheets are presented. The investigation consists of two phases: the first one is focused on the

\footnotetext{
*Address correspondence to this author at the Department of Civil and Mechanical Engineering, University of Cassino and Southern Lazio, Italy; Tel: +39.0776.299.3740; Fax: +39.0776.299.3392;

E-mail:mimbimbo@unicas.it
}

influence of the steel stirrups and the second one concerns the role of the beam slenderness ratio. Some of the results of each phase have been already object of discussion in [26, 30]. Here, the aim of the paper is to globally present the results of the experimental activity and develop a more comprehensive discussion on the following points: (i) effect of the transverse steel amount and the FRP strengthening configuration and (ii) influence of the beam slenderness ratio on the shear contribution of the FRP, with the intent of analyzing and comparing the role of the considered parameters on the resistant mechanism of the examined beams.

It is evident that the number of the tests discussed in the paper is not sufficient to calibrate a theoretical model able to account for the influence of the steel stirrups and the slenderness ratio on the shear contribution of FRP strengthening system. However, the results of the tests have certainly evidenced the role that these parameters could have on the interaction mechanism between the RC beams and the strengthening system, an effect that is completely neglected in actual design formulas.

\section{SPECIMENS, SETUP AND INSTRUMENTATION}

Three series of full-scale RC beams strengthened in shear by carbon fiber reinforced sheets applied on the external beams surface through epoxy resin have been tested (Fig. 1). The beams have been characterized by different strengthening configurations, percentage of steel stirrups, beam slenderness, configuration and instrumentation set up. For all the tested beams, the same concrete mixing, steel reinforcement and reinforcing system (adhesive and FRP) have been used. In particular, a concrete mix consisting of Portland cement was adopted. Compression standard tests have been performed on 45 control standard cubic specimens (dimensions $150 \times 150 \times 150 \mathrm{~mm}^{3}$ ) cast and cured at the same time and under the same conditions of the tested beams according to the indications contained in the Italian document UNI 6132 [31]. The obtained average cylindrical compression strength, $\mathrm{f}_{\mathrm{c}}$, 

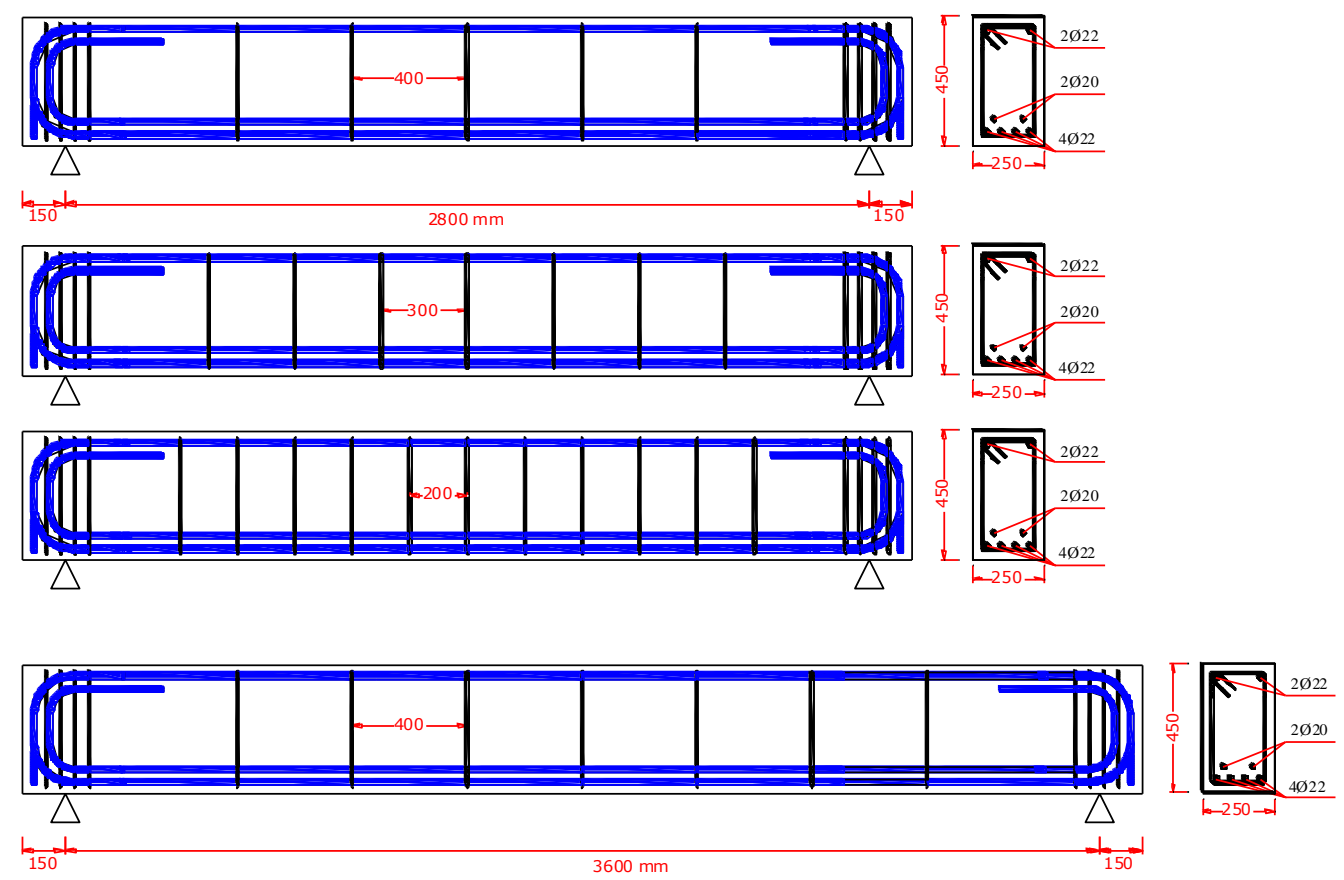

Fig. (1). Geometry and internal steel reinforcements of examined specimens.

obtained by the cubic compressive strength, $\mathrm{R}_{\mathrm{c}}$, using the relation $\mathrm{f}_{\mathrm{c}}{ }_{\mathrm{c}}=0.83 \mathrm{R}_{\mathrm{c}}$, results equal to $21 \mathrm{MPa}$ at the time of beam tests. The steel used for longitudinal and transversal reinforcement was also tested in laboratory according to the Italian code UNI 10002/1 [32]. The test provides a yield strength, $\mathrm{f}_{\mathrm{sy}}$, equal to $476 \mathrm{MPa}$ (corresponding to the Italian standardized FeB44 grade) and a modulus of elasticity equal to $210 \mathrm{GPa}$. The CFRP adopted as reinforcing material is the commercial unidirectional sheet SikaWrap-Med Mod 400C NW with a Young's modulus of $392 \mathrm{GPa}$, a tensile strength value equal to $2600 \mathrm{MPa}$ and an ultimate tensile strain about $0.6 \%$. The CFRP was applied in one ply with a design thickness (consistent with carbon fiber amount) of $0.191 \mathrm{~mm}$ and using a two components epoxy resin.

In addition, the longitudinal steel reinforcement of the beams was designed in order to assure a shear dominate failure mode. It consists of four $22 \mathrm{~mm}$ diameter plus two 20 $\mathrm{mm}$ diameter steel bars at the bottom, and two $20 \mathrm{~mm}$ diameter steel bars at the top of the beam's section (Fig. 1).

\subsection{Series 1}

Series 1 is composed of fifteen full-scale beams with a total span length of $2800 \mathrm{~mm}$ and a rectangular cross-section of $250 \mathrm{~mm}$ wide and $450 \mathrm{~mm}$ deep, corresponding to a shear span-to-effective depth ratio $\lambda=3$. The web reinforcement is constituted by $8 \mathrm{~mm}$ diameter closed steel stirrups placed with three different spacing: $400 \mathrm{~mm}, 300 \mathrm{~mm}$ and $200 \mathrm{~mm}$. The details of the specimens are shown in Fig. (1).

Ten beams were strengthened in shear with CFRP sheets placed perpendicularly to the beam longitudinal axis. The sheets were applied over the external surface along the whole length of the beams by adopting three different strengthening configurations as shown in Fig. (2):

- W (Fig. 2a): complete wrapping with composite sheets surrounding completely the cross section with an adequate overlapping at the junction to prevent its opening;

- U (Fig. 2b): improved U jacketing with main composite sheets surrounding only three sides of the section and an additional strip placed along the upper part of beam to improve the anchorage of FRP sheets. The additional strip is made by the same material of the FRP reinforcement used for the strengthening of the beams and has a fiber orientation parallel to the longitudinal axis of the beam and a width equal to $125 \mathrm{~mm}$;

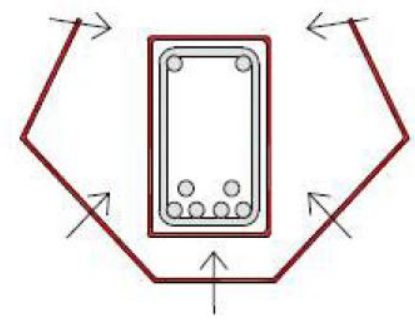

a)

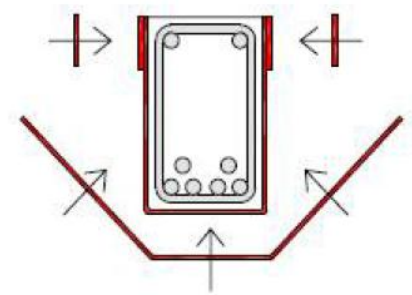

b)

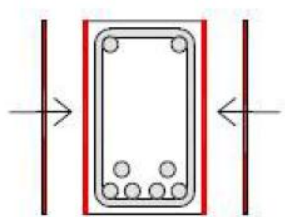

c)

Fig. (2). Strengthening configuration: a) wrapping; b) U-jacketing; c) side bonding. 
- S (Fig. 2c): side bonding with composite sheets placed only at the beam lateral surface.

The remaining five beams were not strengthened and used as control beams (see Table 1).

Each specimen is labeled by a five character designation: RSnWL3, RSnUL3, RSnSL3 and RSnNRL3, where R denotes that the beam has a rectangular section; Sn indicates the stirrup spacing, assuming in our case, the values S4, S3 or S2, standing respectively for 400,300 or $200 \mathrm{~mm}$; W, U, $\mathrm{S}$ and NR indicate the strengthening configuration, previously named as complete wrapping (W), improved U jacketing (U), side bonding (S) or not strengthened (NR); L3 indicates the aspect ratio equal to 3 for all the specimens of this series; finally, the eventual $a$ or $b$ suffix indicating the typology of the instrumentation set-up as detailed in the following. Details of specimens are illustrated in Table $\mathbf{1}$.

All the specimens of series 1 were tested as a simple supported beam subjected to a three-point loading condition as illustrated in Fig. (3). A 1000kN hydraulic jack was used to apply the load at the midpoint. In all specimens, the midpoint deflection was monitored by a vertical displacement transducer. For all specimens, three strain gauges (P1b, P2b, P3b) were mounted on the longitudinal steel bar surface at different positions, and two strain gauges (S1b, S2b) were mounted on two different stirrups. Details of the instrumentation are reported in Fig. (3).

A part from the aforementioned instrumentation common to all the specimens, in only seven beams additional strain gauges were attached directly on the external surface of the FRP sheets (Table 1). The strain gauges were oriented in the vertical direction and located in different sections with the purpose to monitor the strain variation in the FRP. In particular, two different kinds of set-up schemes were adopted, one for the wrapping and $U$ jacketing configuration, and another for the side bonding configuration as shown in Fig. (4).

\subsection{Series 2}

Series 2 is composed of four full-scale beams with a total span length of $3600 \mathrm{~mm}$ and a rectangular cross-section of $250 \mathrm{~mm}$ wide and $450 \mathrm{~mm}$ deep, corresponding to a shear span-to-effective depth ratio $\lambda=4$. The web reinforcement is constituted by $8 \mathrm{~mm}$ diameter closed steel stirrups placed with a spacing equal to $400 \mathrm{~mm}$. The details are shown in Fig. (1).

Table 1. Details of the Examined Specimens

\begin{tabular}{|c|c|c|c|c|c|}
\hline SERIES & Label & Slenderness $\lambda$ & $\begin{array}{c}\text { Stirrups } \\
\text { Spacing }(\mathbf{m m})\end{array}$ & $\begin{array}{l}\text { Strengthening } \\
\text { Configuration }\end{array}$ & Test Instrumentations \\
\hline \multirow{15}{*}{ 营| } & RS4NRL3 & \multirow{3}{*}{3} & 400 & \multirow{3}{*}{ none } & \multirow{3}{*}{$\begin{array}{l}\text { - Strain gauges on the steel } \\
\text { - Displacement transducer at the midpoint of span }\end{array}$} \\
\hline & RS3NRL3 & & 300 & & \\
\hline & RS2NRL3 & & 200 & & \\
\hline & RS4WL3 & \multirow{7}{*}{3} & 400 & \multirow{3}{*}{ Wrapping } & \multirow{7}{*}{$\begin{array}{l}\text { - Strain gauges on the steel } \\
\text { - Displacement transducer at the midpoint of span } \\
\text { - Strain gauges on FRP }\end{array}$} \\
\hline & RS3WL3 & & 300 & & \\
\hline & RS2WL3 & & 200 & & \\
\hline & RS3UL3 & & 300 & & \\
\hline & RS2UL3 & & 200 & U+ jacketing & \\
\hline & RS3SL3 & & 300 & \multirow{2}{*}{ Side bonding } & \\
\hline & RS2SL3 & & 200 & & \\
\hline & RS4NRL3 & \multirow[b]{2}{*}{3} & 400 & \multirow[b]{2}{*}{ none } & \multirow{5}{*}{$\begin{array}{l}\text { - Strain gauges on the steel } \\
\text { - Displacement. transducer at the midpoint of span }\end{array}$} \\
\hline & RS3NRL3 & & 300 & & \\
\hline & RS4UL3 & 3 & 400 & $\mathrm{U}+$ jacketing & \\
\hline & RS4SL3 & \multirow{2}{*}{3} & 400 & \multirow{2}{*}{ Side bonding } & \\
\hline & RS3SL3 & & 300 & & \\
\hline \multirow{4}{*}{ 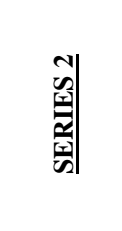 } & RS4NRL4 & \multirow{4}{*}{4} & \multirow{4}{*}{400} & none & \multirow{4}{*}{$\begin{array}{l}\text { - Strain gauges on the steel } \\
\text { - Displacement transducer at the midpoint of span }\end{array}$} \\
\hline & RS4WL4 & & & Wrapping & \\
\hline & RS4UL4 & & & $\mathrm{U}+$ jacketing & \\
\hline & RS4SL4 & & & Side bonding & \\
\hline \multirow{2}{*}{ m } & RS4NRL2.5 & \multirow{2}{*}{2.5} & \multirow{2}{*}{400} & none & \multirow{2}{*}{$\begin{array}{l}\text { - Strain gauges on the steel } \\
\text { - Displacement transducer at the midpoint of span }\end{array}$} \\
\hline & RS4WL2.5 & & & Wrapping & \\
\hline
\end{tabular}


Three beams were strengthened in shear with CFRP sheets placed perpendicularly to the beam longitudinal axis. The sheets were applied over the external surface along the whole length of the beams by adopting the three different strengthening configurations used for series 1 that is complete wrapping (W), improved $U$ jacketing (U) and side bonding (S). The fourth beam was not strengthened and used as control beam (see Table 1). The four beams of this series are labeled RS4WL4, RS4UL4, RS4SL4 and RS4NRL4 (Table 1).

All the specimens of the series 2 were tested as a simple supported beam subjected to a three-point loading condition as illustrated in Fig. (3) as in the case of the beams of the series 1 . In all specimens the midpoint deflection was monitored by a vertical displacement transducer. For all specimens, three strain gauges (Ln1, Ln2, Ln3) were mounted on the longitudinal steel bar surface at different positions, and two strain gauges (St1, St2) were mounted on two different stirrups (Fig. 4).

\subsection{Series 3}

Series 3 is composed of two full-scale beams with a total span length of $2800 \mathrm{~mm}$ and a rectangular cross-section of
$250 \mathrm{~mm}$ wide and $450 \mathrm{~mm}$ deep, corresponding to a shear span-to-effective depth ratio $\lambda=2.5$. The web reinforcement is constituted by $8 \mathrm{~mm}$ diameter closed steel stirrups placed with a spacing equal to $400 \mathrm{~mm}$.

One of the beams was strengthened in shear with CFRP sheets placed perpendicularly to the beam longitudinal axis by using a complete wrapping configuration (W), whilst the other one was not strengthened and used as control beam.

The two beams of this series are labeled RS4WL2.5 and RS4NRL2.5 (see Table 1).

In this case, the beams were tested as a simple supported beam subjected to a four-point loading condition as illustrated in Fig. (3). The four-point loading condition allows to obtain a shear span-to-effective depth ratio $\lambda=2.5$ without changing the length of beams. The same instrumentation used for the specimens of the series 2 has been adopted for series 3 .

\section{EXPERIMENTAL RESULTS AND DISCUSSION}

The results obtained by the tests are discussed in the following section in order to underline the influence of the stir-
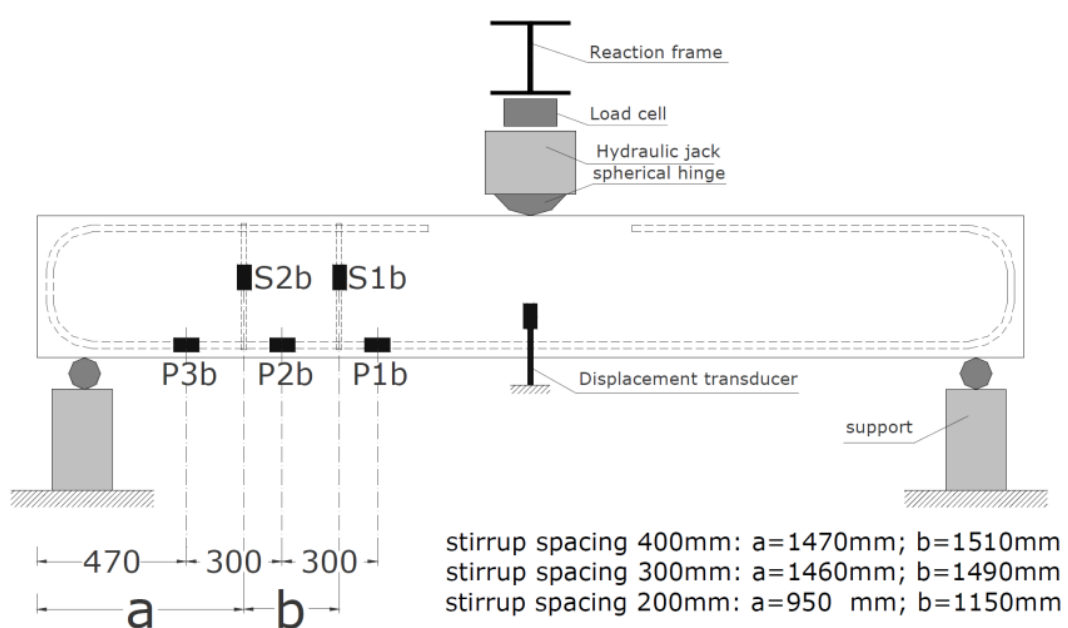

(a)

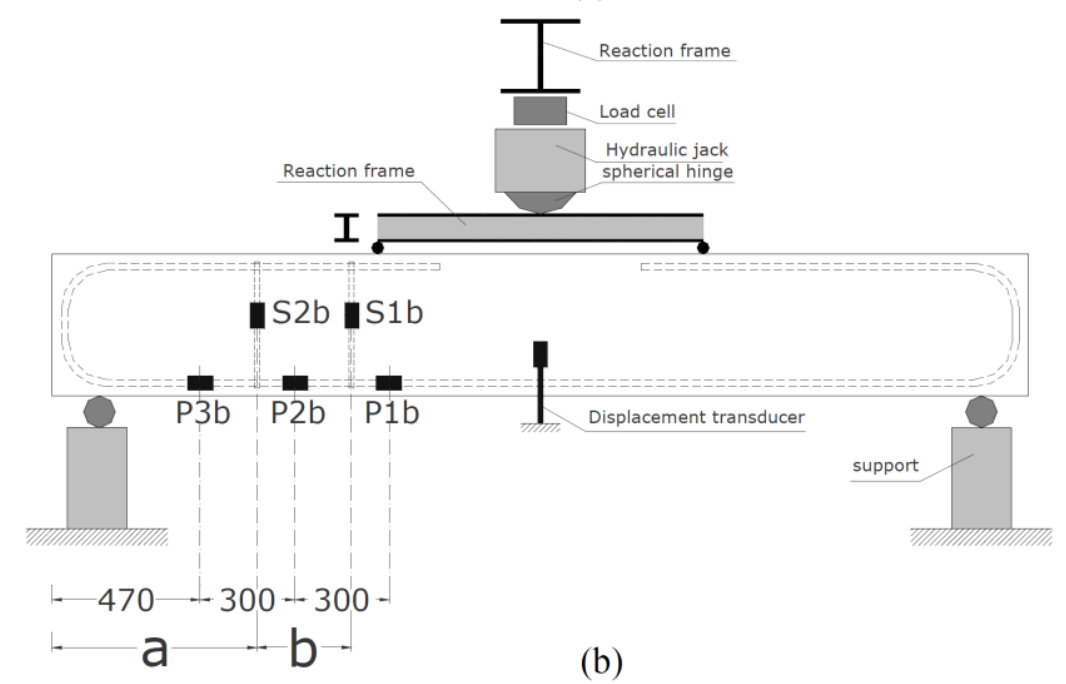

Fig. (3). Additional instrumentation for the beams of the series 1 . 

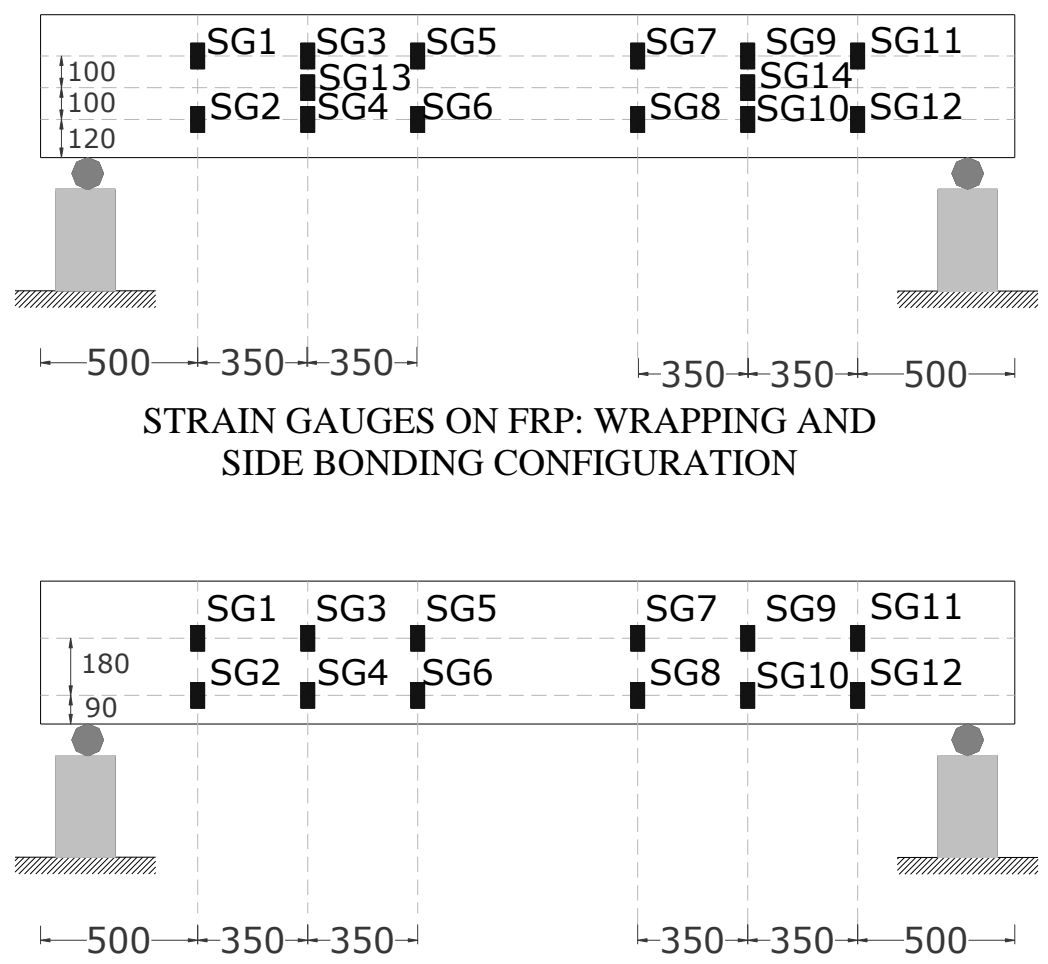

STRAIN GAUGES ON FRP: U-JACKETING CONFIGURATION

Fig. (4). Shear contribution of FRP-strengthening: influence of steel stirrups.

rup spacing, the strengthening configuration and the beam slenderness ratio on the structural response of the FRPstrengthened beams.

In particular, the influence of the stirrups spacing and of the strengthening configuration is examined with reference to the beams of series 1; on the other hand, the influence of the slenderness ratio is analyzed by considering the beams of all the series.

\subsection{Influence of the Stirrups Spacing and of the Strengthening Configuration}

The influence of the stirrups and of the strengthening configuration on the behavior of FRP-strengthened beams is analyzed, particularly considering the strength contribution provided by the FRP and the cracking pattern.

The strength contribution provided by the FRPreinforcement $\left(\mathrm{V}_{\mathrm{FRP}}\right)$ is derived experimentally, for each reinforced beam, by the difference from the ultimate shear of the reinforced specimen and that of the corresponding control beam. The results are reported, by bar graphs, in Fig. (5) in function of the stirrup spacing for the different FRP strengthening configurations. Fig. (5) shows a clear dependency of the FRP shear resisting action on the strengthening configuration and, also, on the amount of the transverse steel reinforcement. The influence of the strengthening configuration is strictly related to the phenomena characterizing the resistant mechanism of the FRP sheets clearly emerged from the tests. In fact, in the case of side bonding configuration, the resistant contribution of the FRP is mainly dependent on the adhesion between the sheets and the concrete, and the failure occurred through a de-bonding mechanism involving the detachment of a thin layer of concrete support. Differently, in the case of the wrapping configuration, both the adhesion and the tensile strength of FRP sheets are involved in the resistant mechanism: the de-bonded zones of sheets continue to contribute to the shear resistant mechanism of beams until the sheets rupture occurs.

From the figure it is evident that, in general, the FRP shear resisting action is smaller in beams with closer steel stirrups with the exception of the fully wrapped specimen with $300 \mathrm{~mm}$ stirrup spacing [26].

In Fig. (6) the cracking pattern is reported at collapse of the specimens. In particular, the figure shows only half span of each beam where the shear rupture occurred. In the figure, the lines represent the crack paths developed in the beams at the collapse, the black area represents the zones where the concrete spalling occurs, and finally, the gray area represents the zones where the de-bonding of FRP sheets occurs.

Fig. (6), in particular the first three columns referring to the beams of the series 1 , shows that the stirrup spacing does not appreciably influence the cracking pattern; on the contrary, the FRP strengthening configuration seems to modify the cracking pattern of the tested beams and, indeed, the non reinforced (NR) beams show a wide cracked area approaching the support zone, whilst the application of FRP generally reduces the concrete area interested by cracks. Moreover, the strengthening configuration also affects the failure mode of beams. In fact:

- in the complete wrapping configuration, the FRP cannot delaminate, so they failed for tensile fracture of the composite sheet applied along the beam side (Fig. 7, a); 


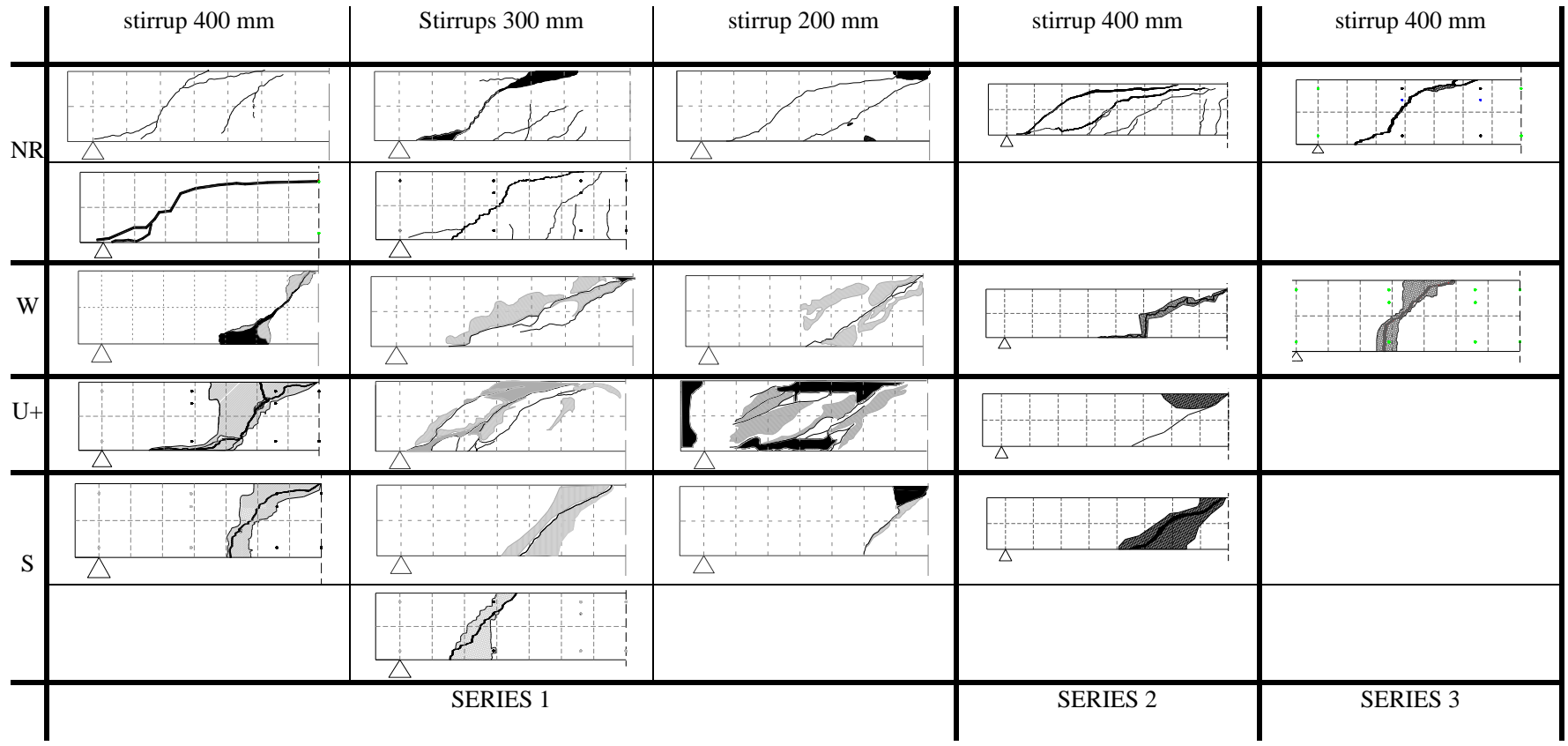

Fig. (5). Cracking configuration at the collapse of the examined beams (concrete spalling - back areas; FRP de-bonding - gray areas).

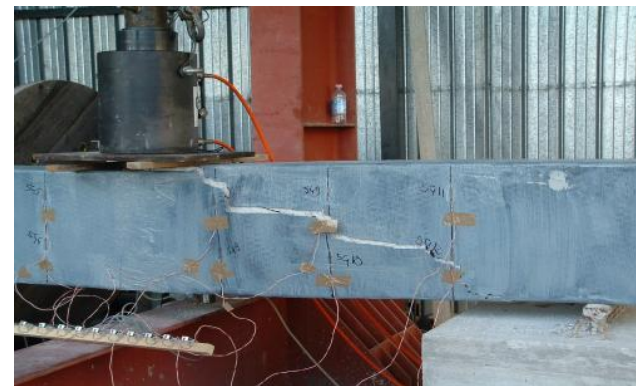

a) wrapping configuration (W)

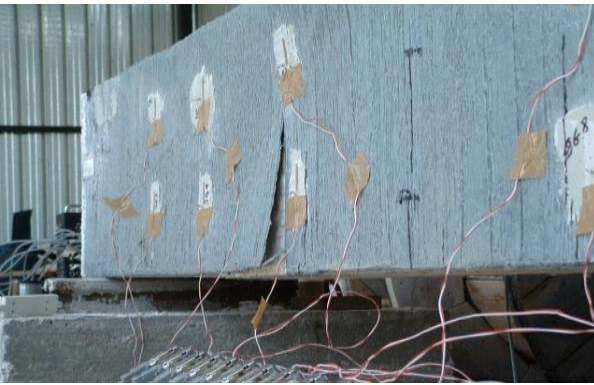

b) side bonding configuration (S)

Fig. (6). Pictures of the failure of the FRP-strengthening for wrapping and side bonding configurations.

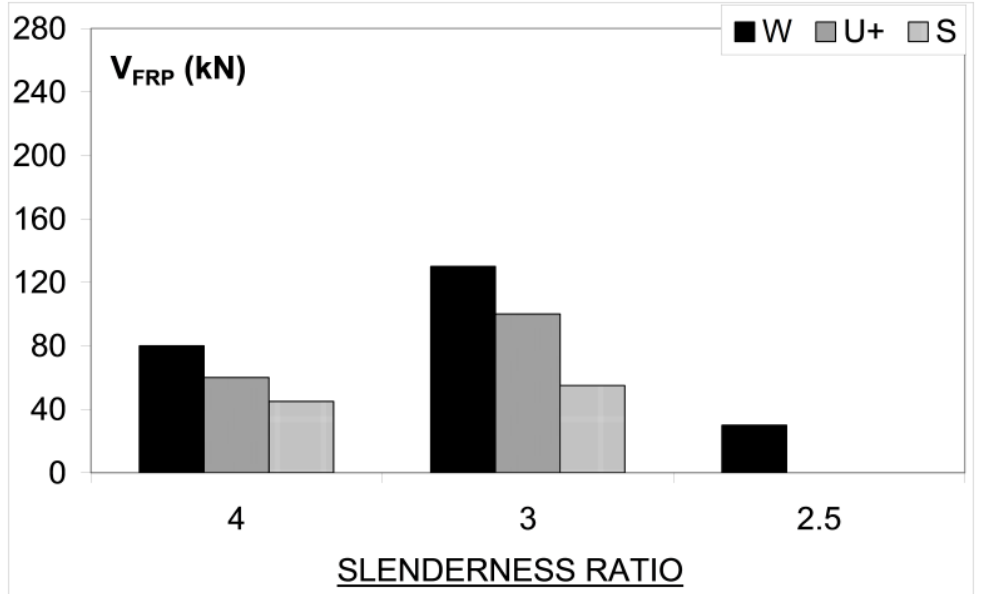

Fig. (7). Shear contribution of FRP-strengthening: influence of slenderness.

- in the improved $\mathrm{U}$ jacketing configuration, the failure occurs only after the rupture of the FRP ring which is followed by the de-bonding of the superior FRP sheet edges not anymore restrained by the ring;
- in the side bonding configuration, for each lateral side two edges are offered to de-bonding, not safeguarded by any kind of mechanical protection (Fig. 7.b).

Further observations can be carried out by examining the measurements of the strain gauges located both on the steel 
Table 2. Maximum Load and FRP Shear Contribution

\begin{tabular}{|c|c|c|c|c|c|c|}
\hline & \multicolumn{3}{|c|}{ maximum Load } & & & \\
\hline & $\lambda=3$ & $\lambda=4$ & $\lambda=2.5$ & \multirow{4}{*}{\multicolumn{3}{|c|}{ FRP-shear contribution $V_{\text {FRP }}$}} \\
\hline & $\mathrm{F}_{\max }[\mathrm{kN}]$ & $\mathbf{F}_{\max }[\mathrm{kN}]$ & $\mathbf{F}_{\max }[\mathrm{kN}]$ & & & \\
\hline RS4NR & $\begin{array}{l}240 \\
250\end{array}$ & 280 & 270 & & & \\
\hline \multirow{2}{*}{ RS3NR } & 320 & & & & & \\
\hline & 320 & & & $\lambda=3$ & \multirow{2}{*}{$\begin{array}{c}\lambda=4 \\
V_{\text {FRP }}[\mathrm{kN}]\end{array}$} & \multirow{2}{*}{$\begin{array}{c}\lambda=2.5 \\
V_{\text {FRP }}[\mathrm{kN}]\end{array}$} \\
\hline RS2NR & 430 & & & $\mathbf{V}_{\text {FRP }}[\mathrm{kN}]$ & & \\
\hline RS4W & 500 & \multirow[t]{3}{*}{440} & \multirow[t]{3}{*}{330} & 130 & \multirow[t]{3}{*}{80} & \multirow[t]{3}{*}{30} \\
\hline RS3W & 660 & & & 170 & & \\
\hline RS2W & 600 & & & 85 & & \\
\hline RS4U & 450 & \multirow[t]{3}{*}{400} & & 100 & \multirow[t]{3}{*}{60} & \\
\hline RS3U & 540 & & & 110 & & \\
\hline RS2U & 560 & & & 65 & & \\
\hline RS4S & 360 & \multirow[t]{4}{*}{370} & & 55 & \multirow[t]{4}{*}{45} & \\
\hline \multirow{2}{*}{ RS3S } & 410 & & & 45 & & \\
\hline & 440 & & & 60 & & \\
\hline RS2S & 480 & & & 25 & & \\
\hline
\end{tabular}

reinforcement and on the FRP-sheets. In particular in the case of FRP-strengthened beams it was observed that:

- the stirrups are not immediately activated when the external load is applied [21].

- in the specimens with the highest amount of the transverse steel ratio, the steel stirrups do not yield.

This last result is in contrast with the instructions of the main code-format recommendations (i.e. $[13,14]$ ) where the shear strength contribution of the transverse steel is evaluated by assuming always the steel yielding.

The strain measurements of FRPs, deduced from the beams of the series 1 , revealed that also the FRP is not immediately activated when the external load is applied but, as opposite of the stirrups, the activation load is not significantly influenced by the amount of the transverse steel ratio [26].

It is important to underline that the above results refer to tests performed on beams, which were un-loaded and uncracked with the consequence of neglecting any pre-stress state acting in the stirrups and in the longitudinal steel bars due to the action of existing loads. This choice was due to a double reason. The first is related to the fact that the strengthening interventions on real structures are generally performed after an un-loading process realized by sustaining the beams through provisory supports with the consequence of reducing the stress state in the concrete and in the steel reinforcement. The second reason refers to the fact that the paper aims at investigating the interaction effects between the steel and the FRP resisting systems without the over imposition of further effects such as the damage level of the concrete and the stress-state of the steel reinforcement, which would tangle the comprehension of such effects, already complex in the case of un-cracked and un-loaded beams. It is evident that, the development of a reliable theoretical model should consider also the effects of pre-loading and pre-cracking states in the structures that affect the interaction mechanisms between steel stirrups and FRP strengthening systems during the various phases of the loading process.

\subsection{Influence of the Beam-Slenderness}

The ultimate load of the specimens are summarized in Table 2, where the relative strength increase $\mathrm{V}_{\mathrm{FRP}}$, is also reported and calculated as difference between the ultimate load of the strengthened beam and the ultimate load of the corresponding control beam. The values of $\mathrm{V}_{\mathrm{FRP}}$ are plotted in Fig. (7) in function of the slenderness ratio of beams. From this figure it is clear the dependency of the strength increase on the slenderness ratio.

In particular, by comparing the strength values of the examined beams (Table 2), the following observations can be carried out:

- the increase of the strength due to the FRP reinforcement is greater for the beams with slenderness ratio $\lambda=3$ in the case of Wrapping and U-jacketing configurations; similar values characterize the beams with side bonding configurations;

- the beam with $\lambda=2.5$ presents the minimum value of the strength increase due to the FRP strengthening.

Similar considerations can be made also in terms of the

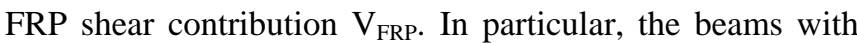
$\lambda=3$ and $\lambda=4$ present FRP shear contributions range between $24 \% \quad(\lambda=4$-side bonding configuration) and 52\% $\quad(\lambda=3$ wrapping configuration); the beam with $\lambda=2.5$ shows a FRP shear contribution equal to $18 \%$.

In Fig. (6) is also reported the cracking pattern at collapse of the specimens of the series 2 and 3. By comparing the cracking configuration of all the specimens it is possible to derive information about the influence of the beam slenderness ratio on the response of the strengthened beams. In particular, the global cracking layout seems to be influenced more by the FRP application than by the beam slenderness, apart for the case of $\lambda=2.5$ which presents its own peculiarities. This observation confirms the fact that the failure mechanism does not vary substantially between beams with $\lambda=3$ and $\lambda=4$. 
Obviously crack angles tend generally to be steeper with $\lambda=3$. This observation could suggest that in the beams with $\lambda=3$ a minor number of steel stirrups are involved in the resistant mechanism and, consequently, a greater contribution of the FRP is expected. In the case of the beam with $\lambda=2.5$ it is also important to underline that a different load scheme is used during the test. In particular, in this case the central part of the beam is characterized by a negligible value of the shear. This is probably mainly responsible for the different trend of the FRP contribution in comparison to the beams with greater slenderness values.

The pattern also confirms that non reinforced beams (NR) have several cracks distributed all along the shear span, whilst reinforced beams (W, U, S) tend to concentrate the damage along one crack (independently on the slenderness ratio).

\section{CONCLUSIVE REMARKS}

This paper has been devoted to investigate the influence that the geometrical percentage of transverse steel reinforcement, the strengthening configuration and the beam slenderness could have on the response of RC beams strengthened in shear by FRPs. For this aim, the results of experimental tests on twenty-one RC beams strengthened in shear by externally bonded CFRP sheets have been presented and discussed.

Among the obtained results the variability of the FRP shear resisting action over the amount of the transverse steel reinforcement has been clearly observed with a FRP shear resisting action generally smaller in beams with closer stirrups.

It has been also observed that FRP application leads to a variation of some of the significant structural aspects like the cracking pattern and the deformation levels in the shear reinforcing system (both steel and FRP), with a possible influence over the resisting mechanisms and, therefore, the final strength.

When considering the effect of slenderness (with fixed amount of steel working in shear) the interaction is, instead, between the contribution provided by the concrete (through the classic arch and beam actions) and the contribution provided by FRP. In this case the trend is less clear. In the case of beams with slenderness equal to 3 and 4 , the slenderness seems to have no influence over failure mode and cracking pattern, two aspects that surely govern the strength response. However, when considering the FRP contribution our experimental campaign shows a peak strength at intermediate slenderness, even if this result may be affected by the not homogenous testing conditions (four vs. three-point loading).

The research represents certainly a first step for a complete understanding of the role of the transverse steel reinforcement and the beam slenderness in the shear resisting mechanism of RC beams strengthened by FRP. Further investigations will be carried out by the authors in the near future with the double aim of analyzing other experimental results, especially within a wider range of beam slenderness, and, also, proposing a simple approach to evaluate the FRP contribution in the shear resistance of such elements.

\section{CONFLICT OF INTEREST}

The authors confirm that this article content has no conflicts of interest.

\section{ACKNOWLEDGEMENTS}

None declared.

\section{REFERENCES}

[1] O. Chaallal, M. J. Nollet, and D. Perraton, "Strengthening of reinforced concrete beams with externally bonded fiber-reinforcedplastic plates: design guidelines for shear and flexure", Can. J. Civil Eng., vol. 25, no. 4, pp. 692-704, 1998.

[2] C. Bakis, L. Bank, V. Brown, E. Cosenza, J. Davalos, J. Lesko, A. Machida, S. Rizkalla, and T. Triantafillou, "Fiber-Reinforced Polymer Composites for Construction-State-of-the-Art Review", J. Comp. Constr., vol. 6, no. 2, pp. 73-87, 2002.

[3] M. J. Chajes, T. F. Janusaka, D. R. Mertz, T. A. Thompson, W. W Finch, "Shear strengthening of reinforced concrete beams using externally applied composite fabrics", ACI Struct. J., vol. 92, no. 3, pp. 295-303, 1995.

[4] Triantafillou TC, "Strengthening of masonry structures using epoxy-bonded FRP laminates", J. Compos. Constr., ASCE, vol. 2, no. 2, pp. 96-104, 1998.

[5] E. Grande, M. Imbimbo, E. Sacco, "Bond Behavior of Historical Clay Bricks Strengthened with Steel Reinforced Polymers (SRP)", Materials, vol. 4, no. 3, pp. 585-600, 2011.

[6] E. Grande, M. Imbimbo, E. Sacco, "Finite element analysis of masonry panels strengthened with FRPs", Composites Part B: Eng., vol. 45, no. 1, pp. 1296-1309, 2013.

[7] E. Grande, M. Imbimbo, E. Sacco, "A beam finite element for nonlinear analysis of masonry elements with or without fiberreinforced plastic (FRP) reinforcements", Int. J. Archit. Herit. Conserv. Anal. Restor., vol. 5, no. 6, pp. 693-716, 2011.

[8] E. Cosenza, and R. Realfonzo, "Flexural performance of RC elements with FRP reinforcement", Compos. Constr. ASCE, pp. 163172, 2001.

[9] J. G. Teng, J. F. Chen, S. T. Smith, and L. Lam, "Behaviour and strength of FRP-strengthened RC structures: a state-of-the-art review", In: Proc of the ICE - Structures and Buildings, 2003.

[10] B. Barton, E. Wobbe, L. R. Dharani, P. Silva, V. Birman, A. Nanni, T. Alkhrdaji, J. Thomas, and G. Tunis, "Characterization of reinforced concrete beams strengthened by steel reinforced polymer and grout (SRP and SRG) composites", Mater. Sci. Eng., vol. 412, no. 1 , pp. $129-136,2005$.

[11] A. Napoli, F. Matta, E. Martinelli, A. Nanni, and R. Realfonzo, "Modelling and verification of response of RC slabs strengthened in flexure with mechanically fastened FRP laminates", Mag. Concrete Res., vol. 62, no. 8, pp. 593-605, 2010.

[12] A. D'Ambrisi, and F. Focacci, "Flexural strengthening of RC beams with cement based composites", J. Compos. Constr., vol. 15 no. 2, pp. 707-20, 2011.

[13] ACI 440. 2R-02, "Guide for the Design and Construction of Externally Bonded FRP Systems for Strengthening Concrete Structures" ACI - American Concrete Institute, Farmington Hills, MI., USA, 2000.

[14] CNR-DT200, "Guide for the design and construction of externally bonded FRP systems for strengthening existing structures. Materials, RC and PC structures, Masonry structures" National Research Council of Italy, Rome, Italy, 2006.

[15] Féderation Internationale du Béton (FIB), "Externally bonded FRP reinforcement for RC structures.” Bulletin 14, Lausanne, Switzerland, 2001.

[16] C. Pellegrino, and C. Modena, "FRP shear resisting of RC beams with transverse steel reinforcement", J. Compus. Constr., vol. 6, no. 2, pp. 104-111, 2002.

[17] S. R. Denton, J. D. Shave, and A. D. Porter, "Shear strengthening of reinforced concrete structures using FRP composites", In: International conference on advanced polymer composites for structural applications in construction. Abington Cambridge, U.K., 2004, pp.134-143. 
[18] J. G. Teng, L. Lam, and J. F. Chen, "Shear strengthening of RC beams with FRP composites", Prog. Struct. Eng. Mater., vol. 6, no. 3, pp. 173-184, 2004.

[19] U. Ianniruberto, and M. Imbimbo, "Role of the reinforced plastic sheets in shear response of reinforced concrete beams: experimental and analytical results", J. Compos. Constr., vol. 8, no. 5, pp. 415-424, 2004.

[20] C. Pellegrino, and C. Modena, "Fiber reinforced polymer shear strengthening of reinforced concrete beams: experimental study and analytical modeling", ACI Struct. J., vol. 103, no. 5, pp. 720$728,2006$.

[21] A. Bousselham, and O. Chaallal, "Effect of transverse steel and shear span on the performance of RC beams strengthened in shear with CFRP", J. Compos. Part B: Eng., vol. 37, pp. 37-46, 2006.

[22] J. F. Chen, G. M. Chen, and J. G. Teng, "Shear resistance of FRPstrengthened RC beams: interaction between internal steel stirrups and external FRP strips", In: ACUN-5 - development in composites: advanced, infrastructural, natural and nano-composites, 2006.

[23] M. Guadagnini, K. Pilakoutas, and P. Waldron, "Shear resistance of FRP RC beams: Experimental study", J. Compos. Construct., ASCE, vol. 10, no. 6, pp. 464-473, 2006.

[24] M. S. Mohamed Ali, D. J. Oehlers, and R. Seracino, "Vertical shear interaction model between external FRP transversal plates and internal steel stirrups", Eng. Struct., vol. 28, no. 3, pp. 381-389, 2006.

[25] A. Rasulo, and M. Imbimbo, "The influence of transverse steel and FRP configurations on the shear behaviour of RC beams", In: Conference Fib06, 2006.
[26] E. Grande, M. Imbimbo, and A. Rasulo, "Effect of transverse steel on the response of RC beams strengthened in shear by FRP: experimental study", J. Compos. Constr., ASCE, vol. 13, no. 5, pp. 405414, 2009.

[27] G. M. Chen, J. G. Teng, J. F. Chen, and O. A. Rosenboom, "Interaction between Steel Stirrups and Shear-Strengthening FRP Strips in RC Beams", J. Compos. Constr., vol. 14, no. 5, pp. 498-509, 2010.

[28] V. Colotti, "Shear Interaction Effect between Transverse Reinforcements in FRP-strengthened RC Beams", Compos. B, vol. 45, no. 1 , pp. 1222-1233, 2013.

[29] C. Pellegrino, and M. Vasic, "Assessment of design procedures for the use of externally bonded FRP composites in shear strengthening of reinforced concrete beams", Compos. B, vol. 45, pp. 727 741, 2013.

[30] E. Grande, M. Imbimbo, and A. Rasulo, "Experimental study on the capacity of RC beams strengthened in shear by CFRP-sheets", In: Fourth International Conference on FRP Composites in Civil Engineering (CICE2008), 2008.

[31] UNI 6132. "Prove distruttive sui calcestruzzi. Prova di compressione." (in Italian) 1972.

[32] UNI EN 10002-1. "Materiali metallici. Prova di trazione. Metodo di prova (temperatura ambiente)." (in Italian) 1992.

Received: April 29, 2013

Revised: June 11, 2013

Accepted: August 22, 2013

(C) Grande et al.; Licensee Bentham Open.

This is an open access article licensed under the terms of the Creative Commons Attribution Non-Commercial License (http://creativecommons.org/licenses/ by-nc/3.0/) which permits unrestricted, non-commercial use, distribution and reproduction in any medium, provided the work is properly cited. 